Invasive Plant Science and

Management

\section{cambridge.org/inp}

\section{Editorial}

Cite this article: DiTommaso A (2019) Editorial for Invasive Plant Science and Management, Volume 12. Invasive Plant Sci Manag 12:1-2. doi: 10.1017/inp.2019.5

\title{
Editorial for Invasive Plant Science and Management, Volume 12
}

\section{Antonio DiTommaso}

Professor and Editor, Soil and Crop Sciences, School of Integrative Plant Science, Cornell University, Ithaca, NY, USA

Our journal Invasive Plant Science and Management continues to serve as an important outlet for research focused on the many facets of invasive plants across the globe, including their biology, ecology, impact, and management. During this past year, you might have noticed that we have moved to the predominant use of Latin binomials when referring to plants and other organisms mentioned in articles. The use of common names is now only listed at first mention in the text. This change will better align our journal with other international journals focused on invasive species and pest management. You might also have noticed the increased use of color figures and photos in our articles, and we encourage submissions that include color figures and photos, as there is no extra cost for their use.

We continue to build the reputation of Invasive Plant Science and Management as a top journal for research and case studies not only on the biology and ecology of invasive plant species, but also on their impacts and management. For example, in each article we feature a "Management Implications" section that provides a succinct summary of the key management implications of the research that can inform adoption of novel practices by land managers and other practitioners. We continue to receive and encourage submissions of well-designed studies on all aspects of invasive plants from all regions of the world. Invited reviews on relevant and timely topics of interest to our readership are also welcome. During this past year, we published several such reviews and hope to have several more in 2019. Of increasing importance to authors is the time frame from the original submission of a manuscript to a first editorial decision. We continue to be very competitive in this regard relative to other journals, averaging 45 days to first decision in 2018. We hope to reduce this time period in the coming year.

I would like to thank the many reviewers and the editorial board of Invasive Plant Science and Management who gave of their precious time and expertise to assure the scientific rigor and accuracy of work published in our journal in 2018 .

\section{Editorial Board 2018}

Edith B. Allen

Jacob N. Barney

John Cardina

Stephen F. Enloe

Songlin Fei

Guillaume Fried

Catherine S. Jarnevich

Marie Jasieniuk

Darren J. Kriticos

James K. Leary

Kelly G. Lyons

Jane M. Mangold

John A. Randall

Rob J. Richardson

Steve S. Seefeldt

Ryan M. Wersal

Invasive Plant Science and Management Reviewers 2018

Pedro Antunes

Daniel Z. Atwater

Kristine Marie Averill

Jacob Barney

Cameron Barrows

Carol Baskin 
Theresa Becchetti Christopher Beck Roger L. Becker Bernd Blossey

Graeme Wayne Bourdot

Graham Brodie

William Bruckart

Janelle M. Burke

Paul Champion

David R. Clements

Kirk W. Davies

Jeffrey F. Derr

Stephen F. Enloe

Jason Ferrell

Alan Franck

Kim Franklin

Susan Galatowitsch

David Gorchov

Elise S. Gornish

Greta Gramig

Sigurdur Greipsson

Charles Halpern

Martin Hejda

Cynthia Huebner

Terho Hyvonen

Kylie Ireland

Jenny Kao-Kniffin

Claude Lavoie

Nevin Craig Lawrence

Erik A. Lehnhoff

Ramon G. Leon

Rodney G. Lym

Kelly G. Lyons

Gregory MacDonald

John D. Madsen

Joy E. Marburger

Glenn Matlack

Brian McCarthy

Peter McEvoy
Ryan W. McEwan

Brian A. Mealor

Mohsen B. Mesgaran

Jean-Yves Meyer

Lindsey Milbrath

Thomas A. Monaco

Jeff Mosley

Riccardo Motti

Anouk N'Guyen

Scott Jay Nissen

Stephen John Novak

Dennis Calvin Odero

Marcela Claudia Pagano

Franklin Dane Panetta

Martin Pavlik

Brooke Pickett

Monique Poulin

Timothy S. Prather

Aman Rana

Corey V. Ransom

Kurt Reinhart

Ian Renne

Mark J. Renz

Lisa J. Rew

Vikki L. Rodgers

Erin Rosskopf

James Russell

Brian J. Schutte

Timothy R. Seastedt

Roger L. Sheley

Evan Siemann

Reid J. Smeda

Daniel R. Tekiela

Kathryn Thomas

Blair Waldron

Donald M. Waller

Sarah Ward

Truman Young

Lewis H. Ziska 